\title{
Rechtsbegriffe
}

\section{Der Rriegsiwirtjad)aft}

(Ein $\mathfrak{B e r}$ juch ber (Grundlegung bez

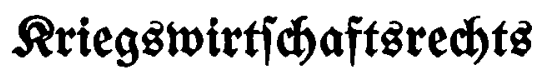

\author{
Bon

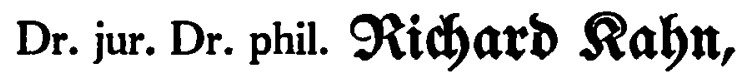 \\ Qubrvigżafen a. $\Re$.
}

\section{8}

Mündyen, Berlin unb Leipzig

3. Gateiber $\mathfrak{B e r l a g}$ (Uatbur Gellier). 


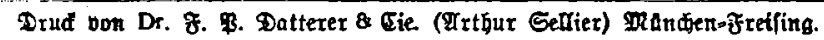


Serrn R. Bebeimen Sofrat

\section{Friebrich $\mathfrak{R r a f f t}$,}

Oberbürgermeifter in Lubmigşhafen a. $\mathfrak{R h}$.

ergebenjt zugeeignet. 
